Check for updates

Cite this: RSC Adv., 2017, 7, 53492

Received 16th October 2017

Accepted 14th November 2017

DOI: 10.1039/c7ra11399d

rsc.li/rsc-advances

\title{
Multi-shape memory effect of polyimides with extremely high strain $\dagger$
}

\author{
Jianan Yao, ${ }^{a}$ Zhao Zhang, ${ }^{a}$ Chunbo Wang, ${ }^{a}$ Shengqi Ma, ${ }^{a}$ Tianqi Li, ${ }^{b}$ Xiaogang Zhao, ${ }^{a}$ \\ Daming Wang, ${ }^{a}$ Hongwei Zhou ${ }^{a}$ and Chunhai Chen (D) *a
}

A simple strategy is provided to construct novel shape memory polyimides with both physical and chemical crosslinks. The resulting materials exhibited an ultrahigh strain and a multiple shape memory effect without sacrificing the shape fixity and recovery, thereby presenting its potential application in the aerospace industry.

Shape memory polymers (SMPs), which are a class of smart materials, can be deformed into temporary shapes and revert to their permanent shapes in response to external stimuli. ${ }^{1-3}$ External stimuli, such as heat, light, electrical, moisture, and $\mathrm{pH}$, are used to initiate shape recovery. ${ }^{4-10} \mathrm{~A}$ variety of stimuliresponsiveness SMPs has been used for biomedical devices, package materials, smart textile materials, and so on. ${ }^{11-14}$ From a structural perspective, polymers designed for shape memory are either thermoplastic (physical crosslinks) or thermoset (chemical crosslinks). Physical crosslinks are produced by chain entanglement, hydrogen bond, or ionic interaction, and can exhibit reversible dissociation and formation, thereby generating thermoplastic SMPs with high strain abilities. However, physical cross-linked polymers exhibit less stability due to the chain sliding or reorganization following deformation, especially following significant changes in shape.$^{15}$ As compared to physical crosslinks, chemically cross-linked networks have rigid structures to restrict chain sliding or reorganization, thereby improving the shape recovery $\left(R_{\mathrm{r}}\right)$ of SMPs. ${ }^{16}$ Meanwhile, the movement of the molecular chains was restricted that high strain of thermoset SMPs hardly to be achieved. However, some papers on chemically crosslinked polymers that have coexisted high strain and high $R_{\mathrm{r}}$ was reported. ${ }^{17-20}$ In this paper, a new type of SMP that utilizes the synergistic effect of both physical and chemical crosslinks, which may exhibit both a high strain and high $R_{\mathrm{r}}$.

Polyimides (PIs) possess outstanding properties such as thermal stability, superior tensile strength, and excellent radiation shielding capability. ${ }^{21}$ Polyimides exhibiting the shape

${ }^{a}$ National \& Local Joint Engineering Laboratory for Synthesis Technology of High Performance Polymer, Key Laboratory of High Performance Plastics, Ministry of Education, College of Chemistry, Jilin University, Changchun, 130012, P. R. China. E-mail: cch@jlu.edu.cn

${ }^{b}$ State Key Laboratory of Supramolecular Structure and Materials, College of Chemistry, Jilin University, Changchun, 130012, P. R. China

$\dagger$ Electronic supplementary information (ESI) available. See DOI: $10.1039 / \mathrm{c} 7 \mathrm{ra} 11399 \mathrm{~d}$ memory effect (SME) might broaden potential applications in the aerospace industry, such as in deployable space structures, shape morphing structures, smart jet propulsion system, hightemperature sensors and actuators. ${ }^{22-28}$ Wang et al. prepared multi-shape memory polyimides by copolymerization, due to its rigid components with an $R_{\mathrm{r}}$ of $95.1 \%$ and a maximum strain of $48.9 \% .{ }^{26}$ Vaia et al. developed dual-shape memory polyimides with a shape fixity $\left(R_{\mathrm{f}}\right)$ of $98 \%$ and an $R_{\mathrm{r}}$ of $98 \%$ using a low crosslink strategy, wherein a strain of $175 \%$ was achieved. ${ }^{29}$ Fully aromatic polyimides exhibit limited strain following deformation because the macromolecular chain possesses rigid chains and strong interchain interactions. ${ }^{30-32}$ These strong interactions originate from the intra- and interchain charge transfer complex (CTC) formations and electronic polarization. In our strategy, the introduction of $-\mathrm{CF}_{3}$ into the alignment of polymer chains' disrupts the formation of efficient CTCs, thereby creating materials with a high strain during deformation. ${ }^{33-35}$ In view of the above-mentioned factors, we selected 2,2'-bis[4-(3-aminophenoxy)phenyl]hexafluoropropane (m-6FBAPP) and 4,4'-(hexafluoroisopropylidene) (6FDA) with fluorinated groups to execute the polymerization reactions. In addition, 1,1,1-tris[4-(aminophenoxy)phenyl]ethane (TAPE) as non-coplanar crosslinker was incorporated into the macromolecular chain to produce chemical crosslinks, of which the detailed synthesis and characterization are shown in the ESI. $\dagger$ As illustrated in the 3D model structures of the crosslinked polyimides (Fig. 1), the formation of long repeating units and highly kinked structures results in massive chain entanglement and a flexible of the macromolecular chain. These produce a sufficient physical crosslink network and a high strain, which fulfills the requirements of the SMP. The chemical crosslinks of polyimides increase the $R_{\mathrm{r}}$ and the non-coplanar structure of TAPE generates an increase in the twisted conformation of the macromolecular chain without sacrificing the strain of SMP. In addition, appropriate chemical crosslinking points must be considered to eliminate any restrictions on the movement of the macromolecular chains to allow a large shape change. Hence, 


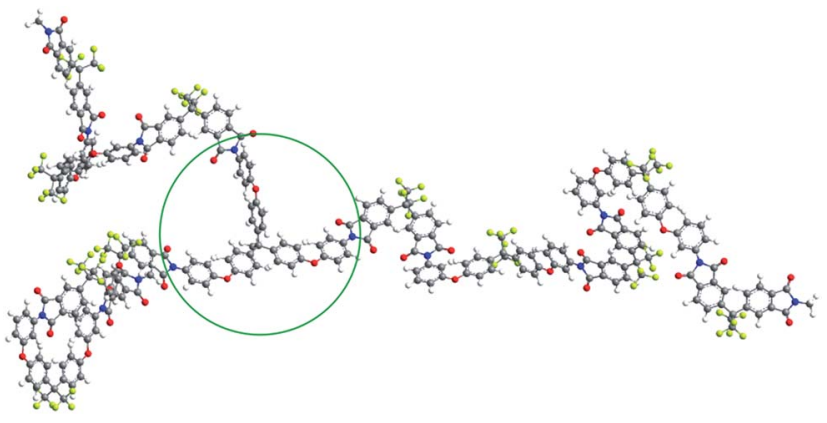

Fig. 1 The 3D model structure of the crosslinked polyimides.

we designed light crosslinked polyimides with appropriate chemical and physical crosslinks. These polyimides not only exhibit strains as high as $460 \%$ with a relatively good $R_{\mathrm{r}}$ of 93.5\%, but also exhibit excellent multi-shape memory effects.

The thermomechanical properties of PI-0 and PI-0.5 (with a $0.5 \%$ mole ratio crosslinker) samples were analyzed by dynamic mechanical analysis (DMA) to characterize their respective shape memory effects (Fig. $2 \mathrm{a}$ and b). No significant difference was observed in the storage modulus $\left(E^{\prime}\right)$ of PI-0 and PI-0.5 at the glass transition, wherein a sharp descent, specifically about three orders of magnitude, from the glassy state to the elastic plateau was observed. Above $300{ }^{\circ} \mathrm{C}$, the curve of the PI-0 storage modulus exhibited a continuous decrease to the viscous state, and the data dropped below the DMA detection limits. However, PI-0.5 exhibited a slow increase, which should be attributed to the incomplete crosslinking of the polyimides following thermal imidization. Various polyimide crosslink densities were also investigated, of which the $\tan \delta$ curves are shown in Fig. S3. $\dagger$ Due to the low crosslink density of the polyimides, little difference in the glass transition temperature $\left(T_{\mathrm{g}}\right)$ was observed. (Table S1†) However, an increase in the crosslink density was observed following a decrease in the height of the $\tan \delta$ peak, which is consistent with previous results on polymers with crosslinked systems. ${ }^{29}$

According to Fig. 2a and b, the dynamical mechanical curves also present shape memory effect information. Both PI- 0 and PI0.5 exhibited a decrease in their storage moduli, by about three orders of magnitude, thereby suggesting that both PI-0 and PI0.5 possess SME. Firstly, we evaluated the dual-SME of the neat PI-0 polyimides (Fig. 2c).

PI-0 exhibited a $432 \%$ strain following deformation and a recovery temperature $\left(T_{\mathrm{d}}\right.$ and $\left.T_{\mathrm{r}}\right)$ of $260{ }^{\circ} \mathrm{C}$ at a fixing temperature $\left(T_{\mathrm{f}}\right)$ of $120^{\circ} \mathrm{C}$, of which a high $R_{\mathrm{f}}$ of $99.6 \%$, a poor $R_{\mathrm{r}}$ of $64.5 \%$, and an about $160 \%$ residual strain was observed. In comparison, PI- 0.5 exhibited a large strain of up to $460 \%$ with a $T_{\mathrm{d}}$ of $260^{\circ} \mathrm{C}$, at a fixing temperature of $120^{\circ} \mathrm{C}$ (Fig. 2d). It had
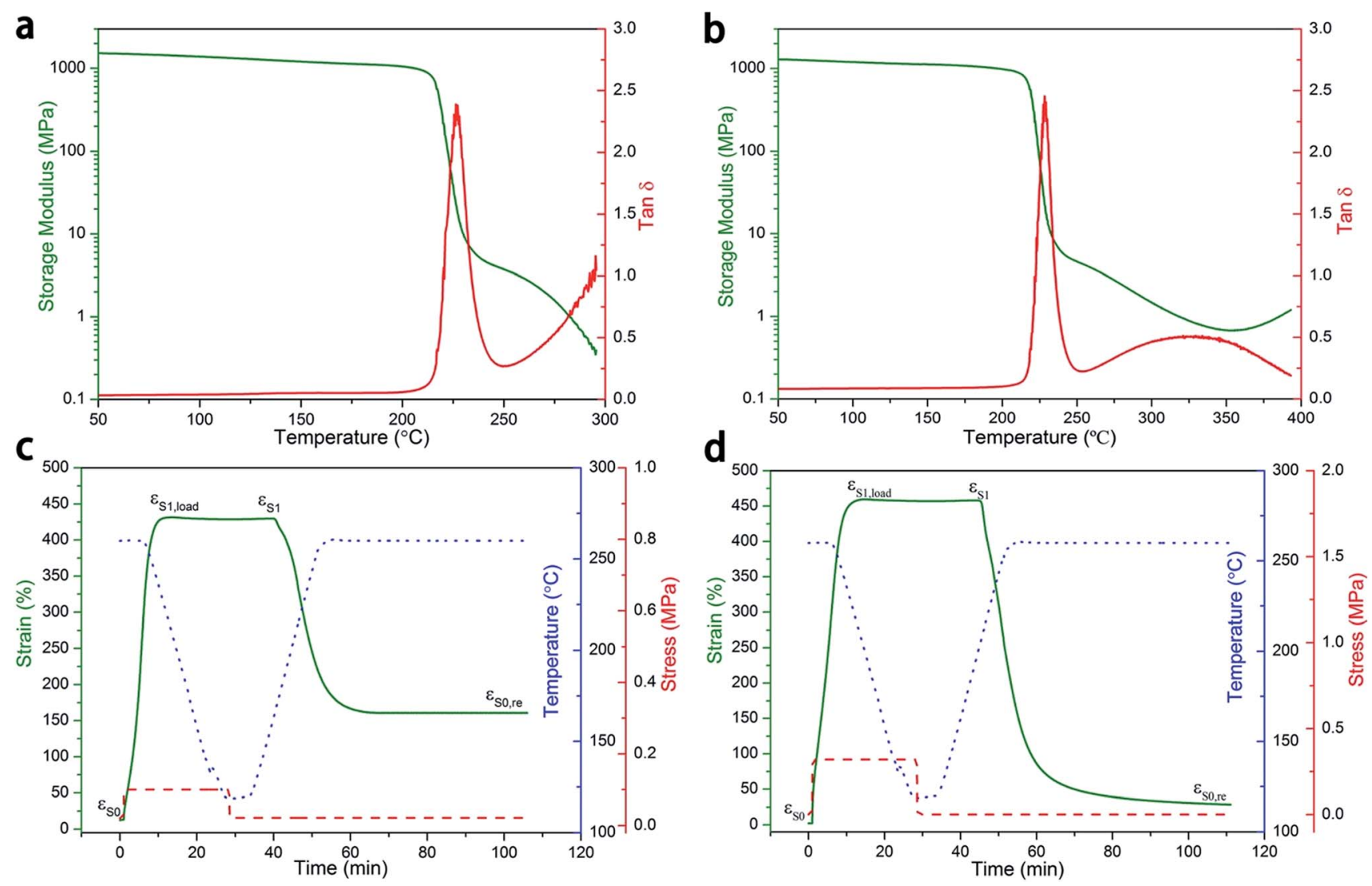

Fig. 2 (a) Dynamic mechanical analysis curve of PI-0. (b) Dynamic mechanical analysis curve of PI-0.5. (c) Dual shape memory cycle for PI-0 at $T_{\mathrm{d}}=T_{\mathrm{r}}=260{ }^{\circ} \mathrm{C}, T_{\mathrm{f}}=120^{\circ} \mathrm{C} . R_{\mathrm{f}}=99.6 \%, R_{\mathrm{r}}=64.5 \%$. (d) Dual shape memory cycle for PI- 0.5 at $T_{\mathrm{d}}=T_{\mathrm{r}}=260^{\circ} \mathrm{C}, T_{\mathrm{f}}=120{ }^{\circ} \mathrm{C} \cdot R_{\mathrm{f}}=99.4 \%, R_{\mathrm{r}}=$ 93.5\%. (See more details of $R_{\mathrm{f}} \mathrm{S}$ and $R_{\mathrm{r}} \mathrm{s}$ in Table $\mathrm{S} 2$ in the ESI $\dagger$ ). Solid line: strain; dotted line: temperature; dashed line: stress. 
a recovery temperature of $260{ }^{\circ} \mathrm{C}$ and exhibited a high $R_{\mathrm{f}}$ of $>99.4 \%$ and a $R_{\mathrm{r}}$ of $>93.5 \%$. According to the results, the presence of triamine in the polyimides was beneficial for shape recovery given that chemical crosslinks restricted the chain from sliding.

The PI crosslinking density is essential in determining its shape memory performance. Therefore, the crosslinking density of PI was investigated over the range of $0.5 \%, 1 \%, 2 \%$, and 5\%, as demonstrated in Fig. S4a-c. $\dagger$ Following an increase in the crosslinking density, the polyimide strain exhibited a decrease from $460 \%$ to $34 \%$, whereas $R_{\mathrm{r}}$ was not increased.

The results of the consecutive dual-shape memory cycling experiments are shown in Fig. S5a. $\dagger$ Four cycles were performed to investigate the effect of the deformation strain on the shape memory properties of PI-0.5 $\left(T_{\mathrm{d}}=T_{\mathrm{r}}=230{ }^{\circ} \mathrm{C}, T_{\mathrm{f}}=120{ }^{\circ} \mathrm{C}\right)$. Each cycle exhibited a high $R_{\mathrm{f}}$ of $>98.6 \%$. In addition, an increase in the thermo-mechanical cycles, exhibited an increase in $R_{\mathrm{r}}$ from $85.5 \%$ to $94.9 \%$, which was similar to the reported research. ${ }^{36,37}$ Notably, the shape memory strain increased following an increase in the number of cycles (Table S3†). This result can be explained by the fact that some macromolecular chains disentangled during stretching, thereby resulting in stress degradation. To compare the effect of the two different crosslinks, PI-5 was also compared to a higher crosslinker with consecutive dual-shape memory cycles (Fig. S5b $\dagger$ ). Obviously, with an increase in the number of cycles, the PI-5 strain exhibited minimal change as compared to PI-0.5. In addition, the $R_{\mathrm{r}}$ of PI-5 was higher than that of PI-0.5 in each cycle, thereby validating the stability of the chemical crosslink as compared to the physical crosslink.

Based on the broad glass transition temperature interval at about $30{ }^{\circ} \mathrm{C}$, a multi-stage recovery test was performed to verify the multiple shape memory effect, as illustrated in Fig. 3a. PI0.5 recovered back to its original shape at a different temperature $\left(220,230,240,250,260{ }^{\circ} \mathrm{C}\right)$, thereby validating the tuning ability of low density crosslinking polyimides at different programming temperatures to achieve multi-shape memory behaviour.

The recovery process of PI-0.5 temporary shape was heated continuously rather than keeping the temperature constant at a certain value, ${ }^{36}$ as shown in Fig. S6. $\dagger$ We found that the tripleshape memory of PI-0.5 recovered back to its original shape continuously with a constant heating, which was corresponding to the multi-stage recovery test. In addition, the triple-shape memory effect of PI-0.5 at different second deformation temperatures was demonstrated in Fig. 3b-d. The permanent shape $\mathrm{S}_{0}$ was first deformed at $260{ }^{\circ} \mathrm{C}$ and fixed at a second transition temperature $\left(220^{\circ} \mathrm{C}, 230{ }^{\circ} \mathrm{C}, 240{ }^{\circ} \mathrm{C}\right.$, respectively) to
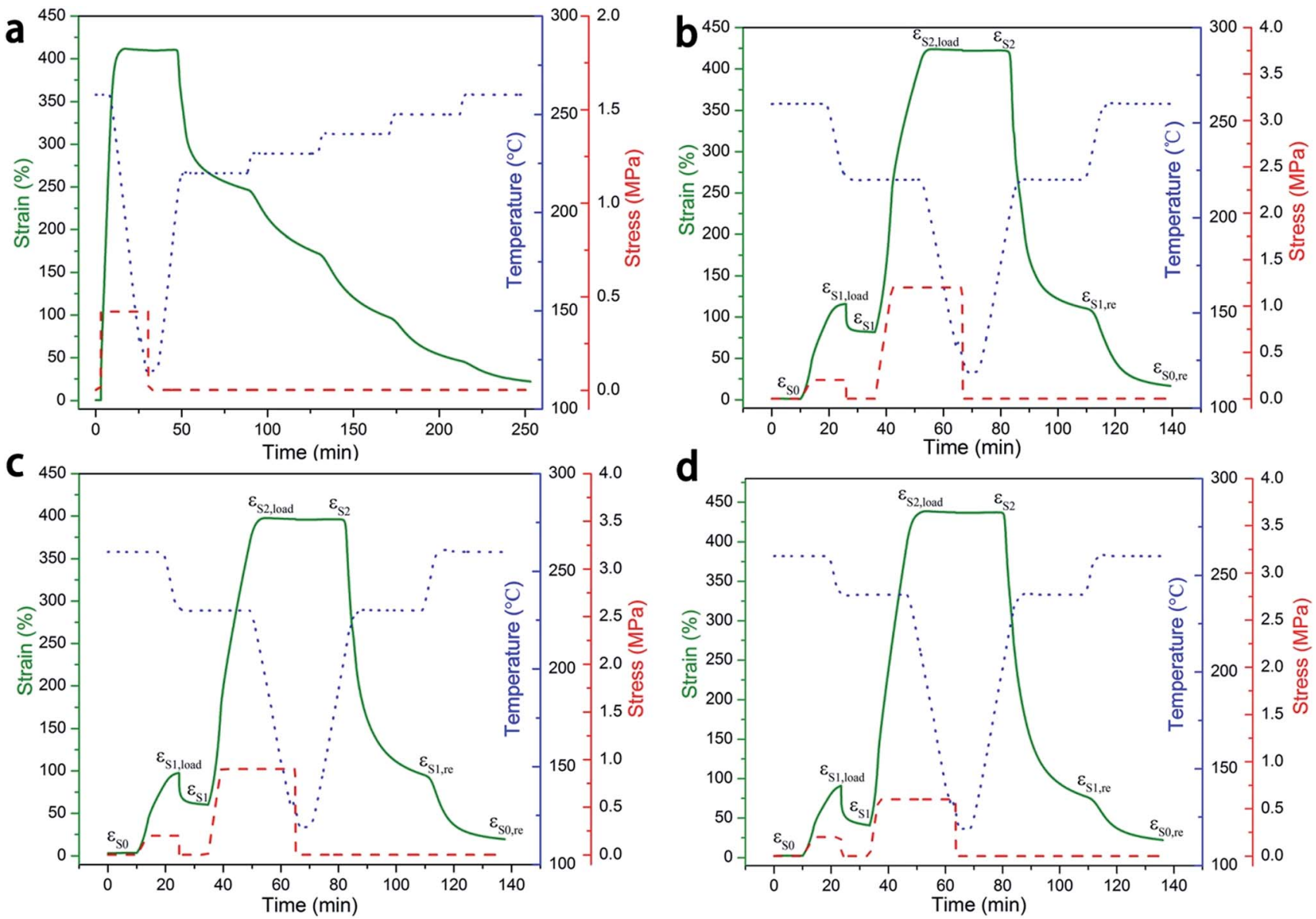

Fig. 3 (a) Multi-stage shape recovery of $\mathrm{Pl}-0.5\left(T_{d}=260^{\circ} \mathrm{C}\right.$ ). Triple-shape memory cycle of PI- 0.5 with: (b) $260^{\circ} \mathrm{C}+220^{\circ} \mathrm{C},(\mathrm{c}) 260^{\circ} \mathrm{C}+230^{\circ} \mathrm{C}$, (d) $260^{\circ} \mathrm{C}+240{ }^{\circ} \mathrm{C}$ (see more details of $R_{\mathrm{f}} \mathrm{s}$ and $R_{\mathrm{r}} \mathrm{s}$ in Table S4 in the ESI $\dagger$ ). 


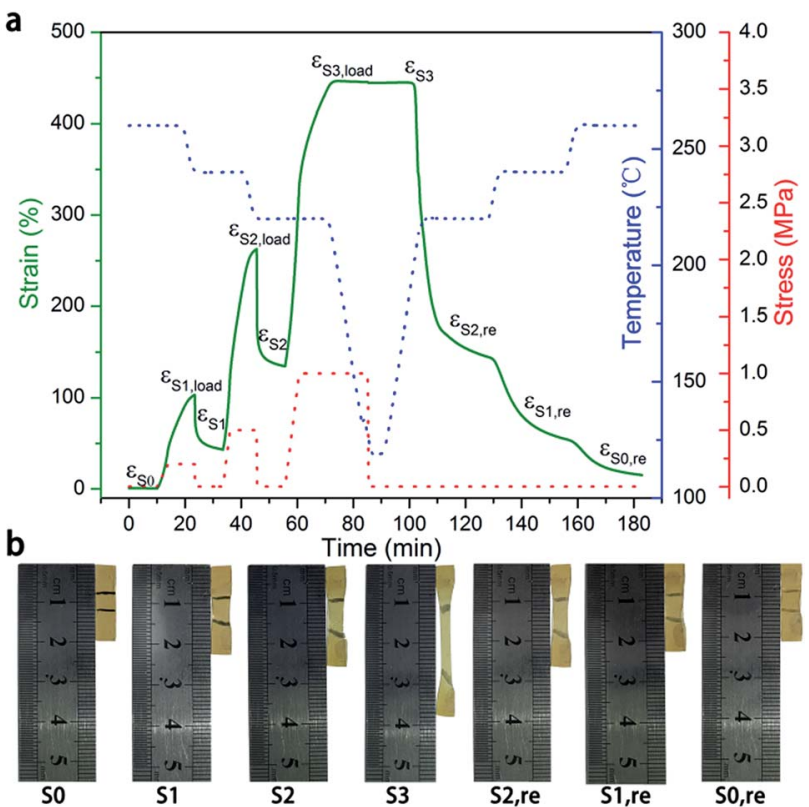

Fig. 4 (a) Quadruple-shape-memory properties of $\mathrm{Pl}-0.5$ with the deformation and recovery temperatures of $260{ }^{\circ} \mathrm{C}+240{ }^{\circ} \mathrm{C}+220^{\circ} \mathrm{C}$ $R_{\mathrm{f}\left(\mathrm{S}_{0} \rightarrow \mathrm{S}_{1}\right)}=41.5 \%, R_{\mathrm{f}\left(\mathrm{S}_{1} \rightarrow \mathrm{S}_{2}\right)}=41.6 \%, R_{\mathrm{f}\left(\mathrm{S}_{2} \rightarrow \mathrm{S}_{3}\right)}=99.3 \%, R_{\mathrm{r}\left(\mathrm{S}_{3} \rightarrow \mathrm{S}_{2, \mathrm{re}}\right)}=$ $96.8 \%, R_{r\left(\mathrm{~S}_{2 \mathrm{re}} \rightarrow \mathrm{S}_{1 \mathrm{re}}\right)}=87.8 \%, R_{\mathrm{r}\left(\mathrm{S}_{1 \mathrm{re}} \rightarrow \mathrm{S}_{0 \mathrm{re}}\right)}=66.2 \%$. (b) Demonstration of triple-SME of PI-0.5 with $260{ }^{\circ} \mathrm{C}+240{ }^{\circ} \mathrm{C}+220{ }^{\circ} \mathrm{C}$.

yield a temporary shape $\mathrm{S}_{1}$ under the same stress with a strain $116 \%$, 97\%, and 91\%, respectively. PI-0.5 was then further stretched at the second transition temperature (STT) and fixed at $120{ }^{\circ} \mathrm{C}$ to yield the temporary shape $S_{2}$ with a final strain of $422 \%, 398 \%$, and $439 \%$, respectively. Upon reheating to the STT and then to $260{ }^{\circ} \mathrm{C}$, the sample recovered to $S_{1 \text {,re }}$ and $S_{0 \text {,re }}$ in sequence, wherein the detailed information are summarised in Table S4. $\dagger$ Interestingly, the first shape fixity was observed at $70.1 \%, 60.3 \%$, and $43.2 \%$ at a STT of $220,230,240{ }^{\circ} \mathrm{C}$, respectively. These results reflect the ability of light polyimides to exhibit triple-SMEs at any temperatures above the onset of the glass transition, though two of the deformation temperatures were farther apart to the benefit $R_{\mathrm{f}}$ and $R_{\mathrm{r}}$.

Heuristically, quadruple-shape memory effects of PI-0.5 were also investigated as shown in Fig. 4a. With the relatively high fixity in quadruple-shape memory, good shape recovery $\left(R_{\mathrm{r}\left(\mathrm{S}_{3}\right.} \rightarrow\right.$ $\left.\left.\mathrm{s}_{2, \text { re }}\right)=96.8 \%, R_{\mathrm{r}\left(\mathrm{s}_{2} \rightarrow \mathrm{s}_{1, \mathrm{re}}\right)}=87.8 \%, R_{\mathrm{r}\left(\mathrm{s}_{1} \rightarrow \mathrm{s}_{0, \text { re }}\right)}=66.2 \%\right)$ were also obtained and the strain up to $446 \%$ when the deformed temperature set as $260,240,220^{\circ} \mathrm{C}$, which is corresponding to the results of multi-stage recovery. The qualitatively characterization with pictures of PI-0.5 taken at different stages of the deformation and recovery process are shown in Fig. $4 \mathrm{~b}$.

\section{Conclusions}

In summary, we designed and fabricated a series of polyimides with relatively good shape memory performance via a traditional polycondensation. As expected, the synergistic effect of physical and chemical crosslinks endowing polyimides with high strain and multi-SME, not deteriorating the perfectly shape fixity and shape recovery. The ease and tunable of these materials might be scaled to the industrial level, given that shape memory polyimides are commercially available for application in aerospace fields.

\section{Conflicts of interest}

There are no conflicts of interest to declare.

\section{Notes and references}

1 M. D. Hager, S. Bode, C. Weber and U. S. Schubert, Prog. Polym. Sci., 2015, 49-50, 3-33.

2 Y. Luo, Y. Guo, X. Gao, B. G. Li and T. Xie, Adv. Mater., 2013, 25, 743-748.

3 Y. Bai, Y. Chen, Q. Wang and T. Wang, J. Mater. Chem. A, 2014, 2, 9169.

4 Y. Y. Xiao, X. L. Gong, Y. Kang, Z. C. Jiang, S. Zhang and B. J. Li, Chem. Commun., 2016, 52, 10609-10612.

5 Y. Wang, X. Li, Y. Pan, Z. Zheng, X. Ding and Y. Peng, RSC Adv., 2014, 4, 17156.

6 S. Chen, Z. Mei, H. Ren, H. Zhuo, J. Liu and Z. Ge, Polym. Chem., 2016, 7, 5773-5782.

7 Q. Zhao, H. J. Qi and T. Xie, Prog. Polym. Sci., 2015, 49-50, 79120.

8 T. Xie, Polymer, 2011, 52, 4985-5000.

9 J. M. Robertson, H. Birjandi Nejad and P. T. Mather, ACS Macro Lett., 2015, 4, 436-440.

10 Z. Wang, Y. Zhang, L. Yuan, J. Hayat, N. M. Trenor, M. E. Lamm, L. Vlaminck, S. Billiet, F. E. Du Prez, Z. Wang and C. Tang, ACS Macro Lett., 2016, 5, 602-606.

11 Q. Zhang, W. Hua and J. Feng, Macromol. Rapid Commun., 2016, 37, 1262-1267.

12 T. Xie, Nature, 2010, 464, 267-270.

13 K. Yu, T. Xie, J. Leng, Y. Ding and H. J. Qi, Soft Matter, 2012, 8, 5687.

14 Y. Zhang, Q. Wang, C. Wang and T. Wang, J. Mater. Chem., 2011, 21, 9073.

15 R. Zhao, T. Zhao, X. Jiang, X. Liu, D. Shi, C. Liu, S. Yang and E. Q. Chen, Adv. Mater., 2017, 29, 1605908.

16 N. Zheng, G. Fang, Z. Cao, Q. Zhao and T. Xie, Polym. Chem., 2015, 6, 3046-3053.

17 T. Raidt, R. Hoeher, F. Katzenberg and J. C. Tiller, Macromol. Rapid Commun., 2015, 36, 744-749.

18 T. Raidt, R. Hoeher, M. Meuris, F. Katzenberg and J. C. Tiller, Macromolecules, 2016, 49, 6918-6927.

19 R. Hoeher, T. Raidt, M. Rose, F. Katzenberg and J. C. Tiller, J. Polym. Sci., Part B: Polym. Phys., 2013, 51, 1033-1040.

20 R. Hoeher, T. Raidt, N. Novak, F. Katzenberg and J. C. Tiller, Macromol. Rapid Commun., 2015, 36, 2042-2046.

21 K. Vanherck, G. Koeckelberghs and I. F. J. Vankelecom, Prog. Polym. Sci., 2013, 38, 874-896.

22 D. Kong and X. Xiao, Sci. Rep., 2016, 6, 33610.

23 M. Yoonessi, Y. Shi, D. A. Scheiman, L.-C. Marisabel, D. M. Tigelaar and R. A. Weiss, ACS Nano, 2012, 6, 76447655 . 
24 Z. Yang, Q. Wang, Y. Bai and T. Wang, RSC Adv., 2015, 5, 72971-72980.

25 X. Xiao, X. Qiu, D. Kong, W. Zhang, Y. Liu and J. Leng, Soft Matter, 2016, 12, 2894-2900.

26 Z. Yang, Y. Chen, Q. Wang and T. Wang, Polymer, 2016, 88, 19-28.

27 Z. Yang, F. Song, Q. Wang and T. Wang, J. Polym. Sci., Part A: Polym. Chem., 2016, 54, 3858-3867.

28 X. Xiao, D. Kong, X. Qiu, W. Zhang, F. Zhang, L. Liu, Y. Liu, S. Zhang, Y. Hu and J. Leng, Macromolecules, 2015, 48, 3582-3589.

29 H. Koerner, R. J. Strong, M. L. Smith, D. H. Wang, L.-S. Tan, K. M. Lee, T. J. White and R. A. Vaia, Polymer, 2013, 54, 391-402. 30 Y. Liu, Y. Xing, Y. Zhang, S. Guan, H. Zhang, Y. Wang, Y. Wang and Z. Jiang, J. Polym. Sci., Part A: Polym. Chem., 2010, 48, 3281-3289.
31 M. Ding, Prog. Polym. Sci., 2007, 32, 623-668.

32 Q. Wang, Y. Bai, Y. Chen, J. Ju, F. Zheng and T. Wang, J. Mater. Chem. A, 2015, 3, 352-359.

33 D.-J. Liaw, K.-L. Wang, Y.-C. Huang, K.-R. Lee, J.-Y. Lai and C.-S. Ha, Prog. Polym. Sci., 2012, 37, 907-974.

34 M. G. Dhara and S. Banerjee, Prog. Polym. Sci., 2010, 35, 1022-1077.

35 M.-D. Damaceanu, C.-P. Constantin, A. Nicolescu, M. Bruma, N. Belomoina and R. S. Begunov, Eur. Polym. J., 2014, 50, 200-213.

36 R. Hoeher, T. Raidt, C. Krumm, M. Meuris, F. Katzenberg and J. C. Tiller, Macromol. Chem. Phys., 2013, 214, 27252732.

37 B. Heuwers, A. Beckel, A. Krieger, F. Katzenberg and J. C. Tiller, Macromol. Chem. Phys., 2013, 214, 912-923. 